\title{
アームコ鉄のフェライト粒子平均直径が超音波 減衰に与える影響について*
}

\author{
椹木義一** 寺石 稔** 明石 一*** 藤井太一**** \\ Influence of Average Diameter for Ferrite Crystallites on \\ Ultrasonic Attenuation in Armco Iron \\ by \\ Yoshikazu SAwaragi, Minoru Teraishi \\ (Faculty of Engineering, Kyoto University, Kyoto) \\ Hajime AkAshi \\ (Faculty of Engineering, Doshisha University, Kyoto) \\ and Taichi FujII \\ (Faculty of Engineering, Osaka City University, Osaka)
}

It is known that the ultrasonic attenuation changes by microstructure and grain size of polycrystalline metals.

Generally, it is considered that the mechanisms that cause loss in metals are mainly elastic hysteresis, forced motion of dislocations and scattering by the grains.

Several authors have reported that ultrasonic attenuation of polycrystalline metals is fit by the equation

$$
\alpha=A_{1} f+A_{2} f^{2}+A_{4} f^{4}
$$

Here $\alpha$ is ultrasonic attenuation, $f$ is ultrasonic frequency, $A_{1}, A_{2}$ and $A_{4}$ are the coefficients. The component proportional to the fequency shows the presence of elastic hysteresis (including motion of magnetic domain wall in ferromagnetic metals). The second term proportional to the second power of frequency is indicative of the motion of dislocation (in this study, the term is negligibly small). The last term proportional to the fourth power of frequency is Rayleigh scattering loss.

The theory of Mason and McSkimin gives the follwing form for $A_{4}$ on longitudinal wave when $\alpha$ is neper/cm :

$$
A_{4}=\frac{2 \pi^{3} T}{v^{4}}<\left(\frac{\Delta K}{K}\right)^{2}>_{A v}
$$

where $T=$ volume of grain, $v=$ velocity of the ultrasonic wave, $K=$ average effective elastic modulus over all directions for propagating the ultrasonic wave in a given direction in a crystallite, $\Delta K=$ difference of the effective elastic modulus from its average as function of direction and $\left\langle(\Delta K / K)^{2}\right.$ $>_{A v}=$ average of the fraction over all directions in the crystallite $(\Delta K / K)^{2}$.

Lifshits, Parkhomovskii and other authors also give the same form as above for $A_{4}$ which is proportional to the third power of grain diameter $D$.

Therefore, we prepared five samples of armco iron with different ferrite grain size.

Transducer was X-cut quartz disk $2 \mathrm{~cm}$ in diameter for longitudinal wave measurement. The attenuation was mesured at the 1,3 and 5 megacycles per second.

Theoretical and experimental results were compared with respect to the attenuation of Rayleigh scatter in specimens.

(Received July 23, 1963)

* 原稿受付 昭和 38 年 7 月 23 日

** 正員 京都大学工学部

*** 正員 同志社大学工学部

**** 正員 大阪市立大学工学部

1. 緒

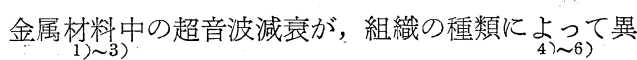
なったり，結晶料子の大きさによって変化することは 
すでによく知られている、これらの原因として考客ら れることは，前者ではお。に弾性履糜や転位の運動あ るいは強磁性体では磁区壁の運動などがあり，後者で は散乱火よるものといわれている。

散乱については, Rayleigh の散乱理論に基づて Mason および McSkimin p Lifshits および Park-

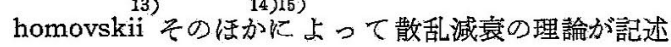
されている．しかしこれらは，いずれも粒子平均直径 の3乗, 周波数の 4 乗比比例するとされている.

そこで本研哭は，アームコ鉄のフェライト粒子直径 を変えることにより，減衰定数がいかに変化するかを

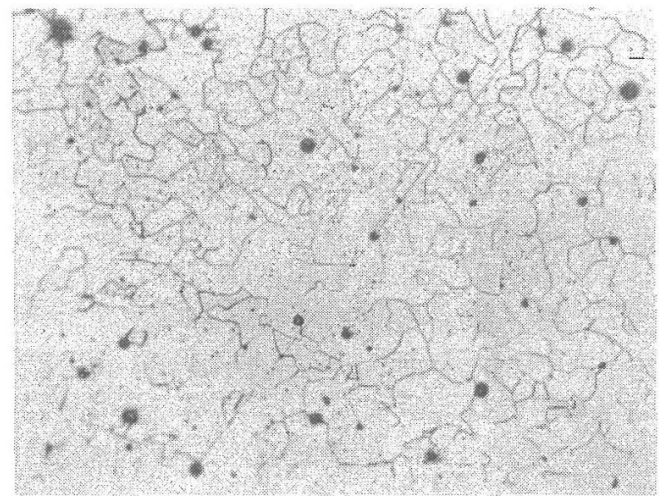

(a)

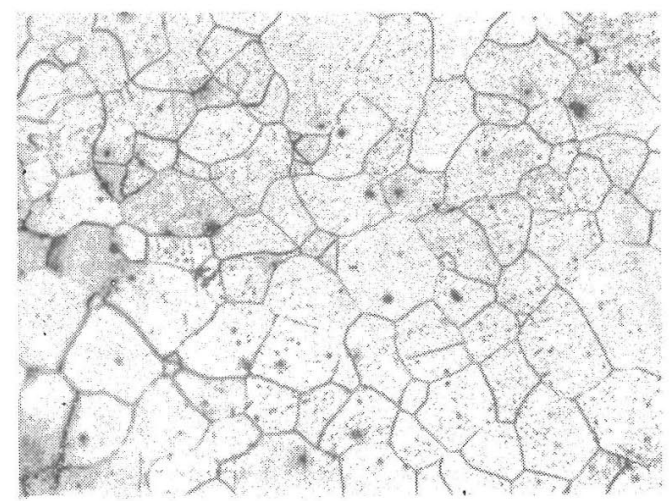

(c)

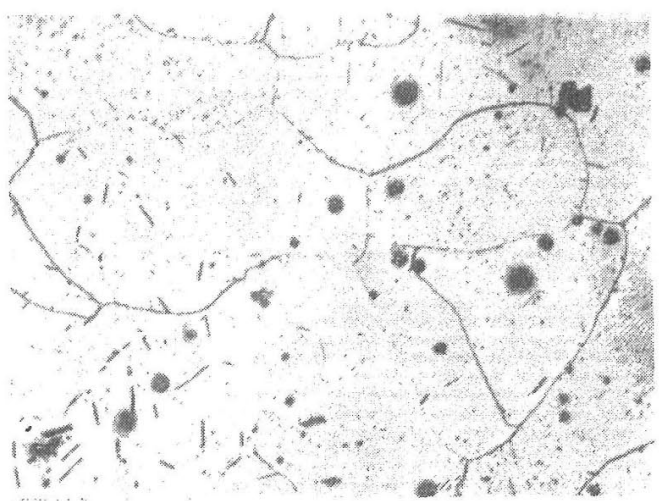

(e)
実験的に求め,これと理論值との比較検討 した。

\section{2. 実 験方 法}

（I）試験片としては，Table 1 に示す化学成分の アームコ鉄で，直径 $25 \mathrm{~mm} \phi$, 長さ $10 \mathrm{~cm}$ のものを 5 本用意し，それぞれ熱処理をすることによりフフェラ

Table 1 Chemical composition of specimen $(\%)$

\begin{tabular}{c|c|c|c|c}
\hline $\mathrm{C}$ & $\mathrm{Si}$ & $\mathrm{Mn}$ & $\mathrm{P}$ & $\mathrm{S}$ \\
\hline 0.03 & 0.26 & 0.05 & 0.005 & 0.008 \\
\hline
\end{tabular}

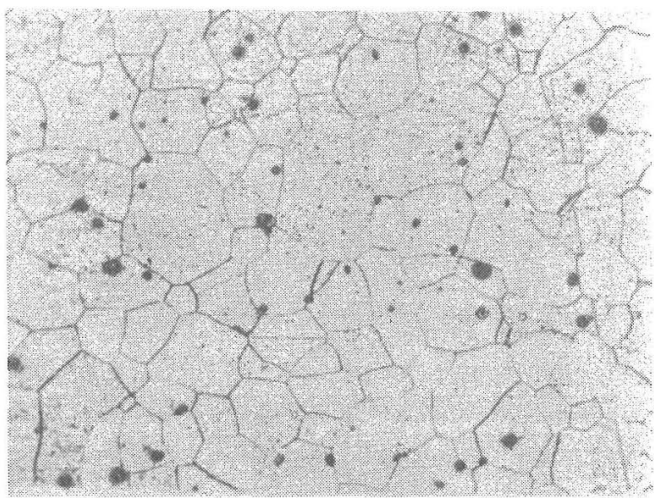

(b)

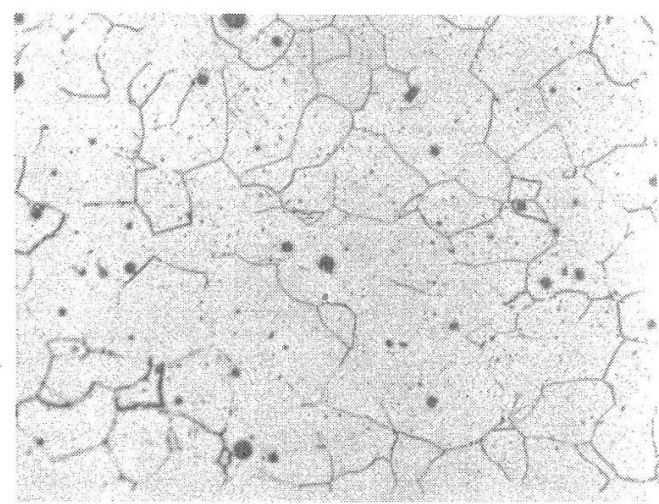

(d)

Photo. 1 Microstructure of specimens subjected to different heat treatment $(\times 100)$ 
イト粒子の大きさを変えた。そしてこれらの組織を Photo. 1 に示すように, 倍率 $\times 100$ の䫟微鏡写真を撮 り, ASTM の比較法によってフェライト粒子平均直 径を求めたものおよび熱処理によって機械的性質も変 化すると思われるので, 念のためマイクロビッカース 硬度計によりフェライト粒子の硬度を求めたものを Table 2 に示す.

（II）測定に使用した超音波の装置は今までのもの と同じで，周波数は $1 ， 3$ および $5 \mathrm{Mc} の 3$ 種類を用 い，それぞれ直径 $2 \mathrm{~cm} \phi, \mathrm{X}$ 一カットの水晶によりマシ ン油を媒体として, 縦波の超音波のパルスを試料端面 より大射し, 反射法により抵抗減衰器で直接デシベル にて読取る力法で測定した.

\section{3. 実 験 結 果}

上に述べた方法により求めた減衰定数の周波数特性 を調べるために, 縦軸に減衰定数を, 横軸に周波数を とり, 粒子直径をパラメーターとしてプロットしたも のを Fig. 1 に示す。これによれば周波数特性は $3 \mathrm{Mc}$

Table 2 Heat treatment, grain size and hardness of specimens

\begin{tabular}{|c|c|c|c|c|}
\hline $\begin{array}{l}\text { Speci- } \\
\text { men }\end{array}$ & $\begin{array}{l}\text { Heat } \\
\text { treatment }\end{array}$ & $\begin{array}{c}\text { ASTM } \\
\text { grain size }\end{array}$ & $\begin{array}{l}\text { Average } \\
\text { diameter } \\
(\mathrm{cm})\end{array}$ & $\begin{array}{c}\text { Micro- } \\
\text { Vickers } \\
\text { hardness } \\
\text { number } \\
(500 \mathrm{~g})\end{array}$ \\
\hline $\mathrm{a}$ & $\begin{array}{l}1050^{\circ} \mathrm{C}, 2 \mathrm{hr} \\
\text { quenched in } \\
\text { water }\end{array}$ & 7 & $3.6 \times 10^{-}$ & 301 \\
\hline$b$ & None & $5 \cdot 5$ & 6 & 193 \\
\hline $\mathrm{c}$ & $\begin{array}{l}1050^{\circ} \mathrm{C}, 2 \mathrm{hr} \\
\text { annealed }\end{array}$ & 5 & $7 \cdot 19$ & 133 \\
\hline $\mathrm{d}$ & $\begin{array}{l}1050^{\circ} \mathrm{C}, 5 \mathrm{hr} \\
\quad \text { annealed }\end{array}$ & $4 \cdot 5$ & $8 \cdot 7$ & 128 \\
\hline e & $\begin{array}{c}1050^{\circ} \mathrm{C}, 10 \mathrm{hr} \\
\text { annealed }\end{array}$ & 2 & 20 & 121 \\
\hline
\end{tabular}

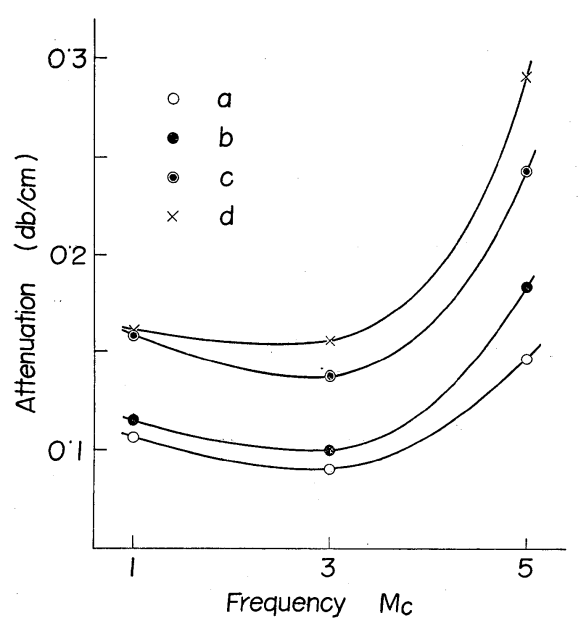

Fig. 1 The attenuation of longitudinal wave plotted as a function of frequency for each specimen
で最小值を示し， $5 \mathrm{Mc}$ にて急激に増大している。そ して粒子直径が大きくなるに従って減衰定数も大きく なっている。なお試料 (e)については減衰が大きく測 定ができなかった。

次に粒子直径と減衰定数との関係を調べるために, 縦軸に減衰定数を，横軸に粒子直径をとり，周波数を パラメーターとしてプロットしたものを Fig. 2 に示 す。これによれば，粒子直径が大きくなるに従って減 衰定数も增大し, 周波数が高いほどその傾きも大きく なっている。

\section{4. 散乱減衰の理論}

Mason および McSkimin によれば，多結晶体中の 超音波減衰定数を次式のように与えている.

$$
\begin{aligned}
\alpha & =A_{1} f_{1}+A_{4} f^{4} \\
\alpha & : \text { 減衰定数 } \\
A_{1}, & A_{4}: \text { 係数 } \\
f & : \text { 周波数 }
\end{aligned}
$$

ここで第 1 項は弾性履歴による損失で, 周波数に比 例し, 強磁性体の場合には磁区壁の運動による損失を も含む.また，第 2 項は散乱によるもので，周波数の 4 乗に比例する。これら以外に場合によっては, 転位 の運動による損失として周波数の 2 乗に比例する項 $A_{2} f^{2}$ を考慮するが，本実験ではほとんど零に近く省 略した。

散乱減衰に対して Mason および McSkimin は縦

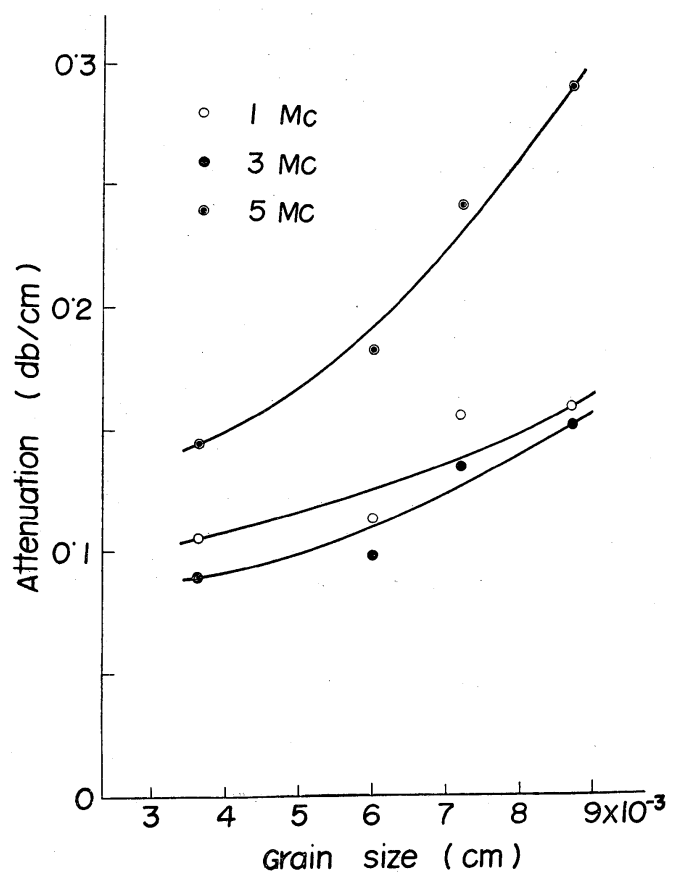

Fig. 2 The attenuation of longitudinal wave plotted as a function of grain size 


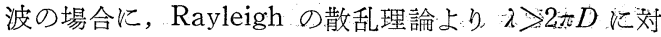
して

$$
A_{4}=\frac{2 \pi^{3} T}{v_{l}{ }^{4}}\left\langle\left(\frac{\Delta K}{K}\right)^{2}\right\rangle_{A v} .
$$

neper $/ \mathrm{cm} / \mathrm{cycle}^{4}$ なる式を誘導している.

ここに $\lambda$ : 波長

$D:$ 粒子直径

$T:$ 粒子体積

$v_{l}:$ 縱波の速度

$\mathrm{K}$ : 媒質の弹性率

$\Delta \mathrm{K}:$ 粒子と媒質との弾性率の差

$\left\langle(\Delta \mathrm{K} / \mathrm{K})^{2}\right\rangle_{A v}$ ：弾性率異方性の空間平均

$$
\left.=\left\langle\left\{\left(C_{11}{ }^{\prime}-\left\langle C_{11}{ }^{\prime}\right\rangle_{A v}\right) / C<C_{11}{ }^{\prime}\right\rangle_{A v}\right\}^{2}\right\rangle_{A v} .
$$

ただし

$$
\begin{gathered}
C_{11}{ }^{\prime}=C_{11}+\left\{2\left(C_{12}-C_{11}\right)+4 C_{44}\right\}\left\{l_{1}{ }^{2} m_{1}{ }^{2}+l_{1}{ }^{2} n_{1}{ }^{2}+m_{1}{ }^{2} n_{1}{ }^{2}\right\} \\
\left\langle C_{11}{ }^{\prime}>_{A v .}=C_{11}+\frac{\left\{2\left(C_{12}-C_{11}\right)+4 C_{44}\right\}}{5}\right. \\
C_{i j}: \text { 各方向にお汀る弾性率 } \\
l, m, n: 3 \text { 応力軸に対する方向余弦 }
\end{gathered}
$$

また，Lifshits および Parkhomovskii によれば

$$
A_{4}=\left(\frac{4 \pi^{4} \mu^{2} D^{3}}{1125 \rho v_{l}^{3}}\right)\left(\frac{2}{v_{l}{ }^{5}}+\frac{3}{v_{t}{ }^{5}}\right)
$$

neper $/ \mathrm{cm} / \mathrm{cycle}^{4}$ である.

ただし

$$
\begin{aligned}
& \rho: \text { 密度 } \\
& v_{t}: \text { 横波の速度 } \\
& \mu: \text { 弹性率 } \\
& \quad=C_{11}-C_{12}-2 C_{44}
\end{aligned}
$$

このほかにも Bhatia および Moore などの理論も あるが，いずれも粒子直径の 3 乗, 周波数の 4 乗に比 例している。すなわち(1)式の第 2 項は

$$
A_{4} f^{4}=A D^{3} f^{4}
$$

である。

\section{5. 考察}

（I）そこで実験結果において，3および $5 \mathrm{Mc} の$ 減衰定数が(1)式に従うものと考元, 弾性履歴の項お よび散乱の項に分けたものを Fig. 3 に示す：これに よれば,これらの項以外の損失(点線で示したもの)が $1 \mathrm{Mc}$ から $3 \mathrm{Mc}$ の間に現われているが，これ柱水晶の 指向性による拡散の影響と考えられる。すなわち, 直 径 $R$ の円板水晶を用いたとすれば，大部分の超音波勢 力が集中する円錐の頂角 $2 \theta_{0}$ は

$$
\sin \theta_{0}=1 \cdot 2 \frac{\lambda}{R}
$$

17)

である。したがって，媒質中の波長入が小さくなるほ ぞ，すなわち周波数 $f$ が大さくなるほど指向性ビーム は鋭くなる。（5)式によれば1〜3Mc 付近では急激に 指向角が変化するが，3～5 Mc ではあまり顕著な変化

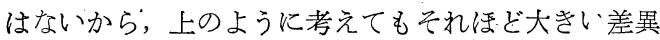

被相。

（II） Fig. 3 によれば，散乱による損失は弾性履歴 の項に比して $3 \mathrm{Mc}$ では $5 \%$ 以下で非常に小さく, 5 Mcでは試料（d)が $20 \%$ ，(c)が $10 \%$ ，ほかはほと んど問題にならない程度である。

さて,ここで散乱減衰の係数について理論值と実験 値とを比較してみると，実験值については Table 3 に示すようで, 理論值については, 単位を揃えるため に(2)，(3)式よりそれぞれ

$$
\begin{aligned}
& \left.A=\frac{2 \cdot 89 \pi^{4}}{v_{l}^{4}}\left\langle\left(\frac{\Delta K}{K}\right)^{2}\right\rangle\right\rangle_{A v} . \\
& A=\frac{0.0308 \pi^{4} \mu^{2}}{\rho^{2} v_{l}^{3}}\left(\frac{2}{v_{l}^{5}}+\frac{3}{v_{t}^{5}}\right)
\end{aligned}
$$

$\mathrm{db} / \mathrm{cm} / D^{3} f^{4}$ とし，これらの式に $\mathrm{Fe}$ に対する值

$$
v_{l}=5850 \times 10^{2} \mathrm{~cm} / \mathrm{sec}
$$$$
v_{t}=3230 \times 10^{2} \mathrm{~cm} / \mathrm{sec}
$$

$\left\langle\left(\Delta K / K^{2}\right)\right\rangle_{A v}=6 \cdot 7 \times 10^{-3}$

$$
\begin{aligned}
& \mu=C_{11}-C_{12}-2 C_{44} \\
& C_{11}=23 \cdot 7 \times 10^{11} \text { dynes } / \mathrm{cm}^{2}
\end{aligned}
$$

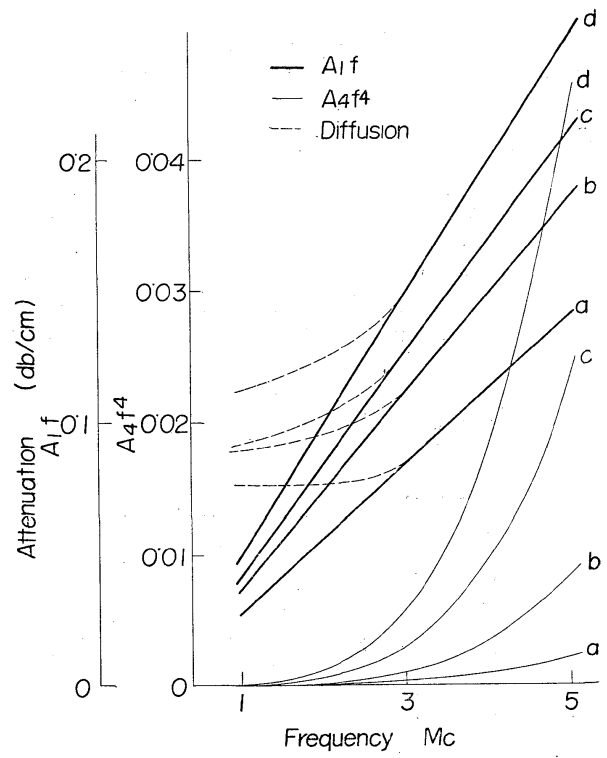

Fig. 3 The terms in Eq. (1) for experimental result as functions of frequency

Table 3 Coefficients $A_{1}$ and $A$ calculated from experimental result

\begin{tabular}{c|c|c}
\hline Specimen & $A_{1} \mathrm{db} / \mathrm{cm} /$ cycle & $A \mathrm{db} / \mathrm{cm} / D^{3}$ cycle $^{4}$ \\
\hline $\mathrm{a}$ & $2 \cdot 86 \times 10^{-8}$ & $7 \cdot 29 \times 10^{-23}$ \\
$\mathrm{~b}$ & $3 \cdot 73$ & $5 \cdot 99$ \\
$\mathrm{c}$ & $4 \cdot 23$ & 10.02 \\
$\mathrm{~d}$ & 4.98 & $10 \cdot 74$ \\
$\mathrm{e}$ & - & - \\
\hline
\end{tabular}

「材料」第 12 巻第 122 号 
$C_{12}=14 \cdot 1 \times 10^{11}$ dynes $/ \mathrm{cm}^{2}$

$C_{44}=2 \cdot 84 \times 10^{11}$ dynes $/ \mathrm{cm}^{2}$

$\rho=7 \cdot 7 \mathrm{~g} / \mathrm{cm}^{3}$

を代大して計算すると $\left(2^{\prime}\right)$ 式より

$$
A=1 \cdot 61 \times 10^{-23} \mathrm{db} / \mathrm{cm} / D^{3} f^{4}
$$

また $\left(3^{\prime}\right)$ 式より

$$
A=3 \cdot 42 \times 10^{-23} \mathrm{db} / \mathrm{cm} / D^{3} f^{4}
$$

となる。

これの違いは $\left(2^{\prime}\right)$ 式では縦波のいくらかが，媒質中 において横波にモード変換するための損失が考慮され ていないので小さくなっている。

これらはいずれも実験值より小さいが，比較的近い 值となっている．この相違の原因として考えられるこ とは

（1）実験の場合に粒子の形状が完全な球状でなく， 粒子直径にばらつきがある。

（2） 3 および $5 \mathrm{Mc}$ の範囲で，拡散による損失を 無視した。

（3）材料が純粋な Fe でなくほかの不純物が混大 している。

（4）計算值では，熱処理による影響を考慮してい ない。

などである。

（III）次に弾性履歷の項についてみると，粒子直径 が大きくなるに従って傾きが大きくなっている。 すなわち， $A_{1}$ が大きくなっている。このことはおそ らく熱処理によって, 機械的な諸性質が変化したため と思われる。

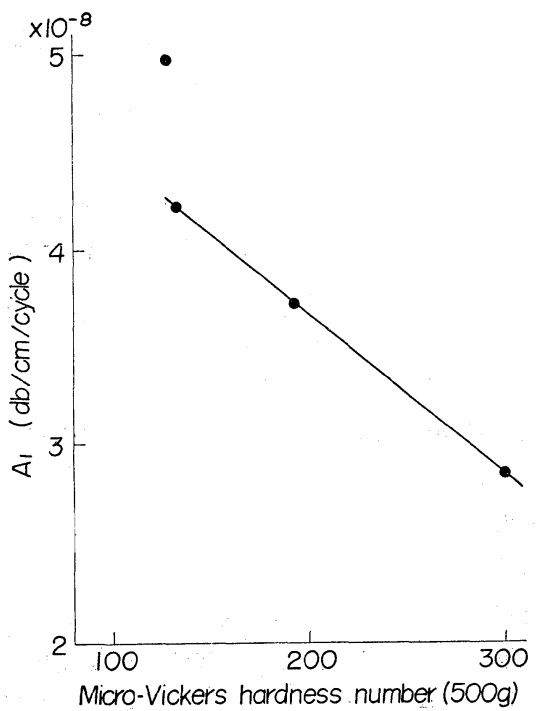

Fig. 4 The coefficient of elastic hysteresis $\mathrm{A}_{1}$ vs Vickers hardness number of ferrite grain
そこで一例として硬度との関係を見るために縦軸に $A_{1}$ を樻軸にビッカース硬度を取ったものを Fig. 4 に 示す。これによれば $A_{1}$ と硬度 $H_{V}$ との関係は

$$
A_{1}=-a H_{V}+b
$$

となり, 本実験値では

$$
A_{1}=-1 / 79 H_{V}+8 \cdot 79\left(\times 10^{-8} \mathrm{db} / \mathrm{cm} / \text { cycle }\right)
$$

なる単純な関係となった。

この原因としては, 硬度が大きくなるに従って, 結 晶粒や，磁区壁の運動が拘吏されるために損失が少な くなるものと考えられる。

\section{6. 結言}

以上の結果より本実験の範囲内において，次のよう なことが結論される。

（1）拡散による損失を除けば，超音波滅吉定数は (1) 式に従う.

（2），散乱による減衰は，弾性履歴（磁区壁の運動 を含む)による減衰に比べ， $3 \mathrm{Mc}$ では $5 \%$ 以下， $5 \mathrm{Mc}$ では(d)が $20 \%$ ，(c)が $10 \%$ 程度で，ほかは非常に 小さい。

（3）散乱隇衰の実験值と理論值は比較的近い值と なった。

（4）弾性履歴の項は，硬度と単純な関係がある.

終りに本実験のために試料を提供していただいた新 日本工機(株)岬工場に対し深謝の意を表する。

\section{参 考 文 献}

1) E.P. Papadakis, J. App1. Phys., 30, 1463 (1959;

2) 広根, 神垣, 金属学会誌, 18, 185 (1954)

3) E.P. Papadakis and E.L. Reed, J. Appl. Phys., 32, 682 (1961)

4) W.P. Mason and H.J. McSkimin, J. Acaus. Soc. Am., 19, 464 (1947), J. Appl. Phys., 19, 940 (1948)

5) 広根, 神垣, 金属学会誌, 17, 412 (1953), 18, 483 (1954)

6) E.P. Papadakis, J. Appl. Phys., 34, 265 (1963)

7) 4) 飞同じ

8) A. Granato and K. Lücke, J. Appl. Phys., 27, 583, $789 \cdot(1956)$

9) A. Granato and R. Truel, J. Appl. Phys., 27. 1219 (1956)

10) W:J. Bratina, U.M. Martius and D. Mills, J. Appl. Phys., 31, $241 \mathrm{~S}$ (1960)

11) U.M. Martius and W.J. Bratina, J. Appl. Phys., 32, $280 \mathrm{~S}$ (1961)

12）干潟，機栈試虽所所報，8，45（1954）

13）実吉, 菊地, 能本, 超音波技術便覧, $940(1960)$ 日刊工業

14) A.B Bhatia, J. Acous. Scc., Am., 31, 16 (1959)

15) A.B. Bhatia and R.A. Moore, J. Acous. Soc. Am., 31, 1140 (1959)

16）たと党ば，椹木；明石，藤井，寺石；材料誠験， 6，534（1957） 日本機械学会論文集, 24, 161 (1958)

17）学術桭興会編, 超音波探侮法, 9 (1956) 丸善

18) W.P. Mason, Piezoelectric Crystals and Their Application to Ultrasonics, 417,425 (1954), D. Van Nostrand

19) 13)の 1319 